\title{
MICROBIOLOGICAL PROFILE OF HOSPITAL ASSOCIATED BLOOD STREAM INFECTIONS IN A NEONATAL UNIT OF A TERTIARY CARE HOSPITAL IN DELHI, INDIA
}

\author{
R. Dutta ${ }^{1}$, K. Gupta ${ }^{1}$, V.S. Randhawa ${ }^{1}$, A. Saili ${ }^{2}$, A.K. Dudeja ${ }^{2}$, S. Khare ${ }^{3}$ \\ ${ }^{1}$ Microbiology, ${ }^{2}$ Pediatrics, Lady Hardinge Medical College, ${ }^{3}$ Microbiology, National Centre for Disease \\ Control, Delhi, India
}

Background and aims: Limited data on microbiological profile of Hospital Associated Blood Stream Infections (HA-BSIs) in neonates in India led to the present one year prospective study at Lady Hardinge Medical College and Shrimati Sucheta Kriplani and Kalawati Saran Children's Hospitals, Delhi.

Methods: The inclusion criteria were

(1) age: 0 to 28 days,

(11) stay beyond 48 hours of admission,

(111) no congenital malformations,

(IV) absence of known maternal risk factors for early onset of neonatal sepsis. Clinical sepsis was diagnosed as per CDC guidelines. In addition to conventional blood culture, Hep-2 cell lines were inoculated for isolation of enteroviruses. Antibodies to coxsackievirus B1-B6 and parvovirus B-95 were determined. Antimicrobial susceptibility testing was done for the bacterial isolates using CLSI guidelines. Risk factors were analyzed using EpiInfo software.

Results: Out of 591 neonates enrolled, 57 episodes of HA-BSIs occurred in 56 neonates (9.64 infections per 100 admissions), 36 being laboratory confirmed BSIs (LCBIs). 40.3\% cases occurred in March- April and $64.9 \%$ on day $3 / 4$ of admission. The commonest clinical signs were lethargy (LCBIs) and hypothermia (clinical sepsis). LCBIs were caused by gram negative bacilli (72.2\%), gram positive cocci (22.2\%) and Candida spp. (5.6\%). Higher drug resistance was observed in gram negative bacilli as compared to gram positive cocci. Klebsiella spp. was the most frequently isolated pathogen. Viral etiology could not be established in any case.

Conclusion: Drug resistant Klebsiella spp. was the key pathogen followed by Acinetobacter spp. causing HA-LCBIs. 